\title{
Strategies for Establishing Normalization and Institutionalization of Campus Football in Colleges and Universities
}

\author{
Peng Lijun \\ (Ji'an College, Ji'an, 343000)
}

\begin{abstract}
Keywords: Colleges and universities; Campus football; Normalization; Institutionalization; Construction
\end{abstract}

\begin{abstract}
The development of Chinese football cannot be separated from the cultivation of young football players. In order to cultivate more young football players, China has proposed the development of campus football culture. This paper analyzes the development of campus football in our country by using the method of literature and data, and believes that the construction of campus football culture in our country must be brought into an institutionalized and normalized development track in order to ensure the orderly and sustainable development of campus football and provide a backup force for the development of our country's football cause.
\end{abstract}

\section{Introduction}

Campus football is an effective breakthrough in our country's sports reform. To innovate the development mechanism of campus football and improve the normalization of the teaching and training of campus football, we need to start with the system of campus football, the teaching of campus football, the training of campus football and the training of talents of campus football. On the basis of implementing all the work of campus football in an all-round way, building a working system which is conducive to the normalization and institutionalization of campus football is an important way to achieve the rapid, efficient and sustainable development of campus football in China. Therefore, this paper takes campus football as the research object, combines the daily teaching and training of campus football, and launches the strategy of establishing normalization and institutionalization of campus football. Through this study, we hope to provide useful reference for better promoting the development of campus football in our country.

\section{The Concept of Campus Football and the Campus Football Culture}

The Origin of Campus Football. The development of campus football in our country can be traced back to the slogan "touch the world" which was put forward by FIFA in the plan of grassroots football. It emphasizes that any teenager, male or female, who is interested in football has the opportunity to participate in systematic football training and football matches. The goal of the slogan is to make football games ubiquitous, so that everyone can participate in football equally, so that football will no longer be far from the people and will develop into a fair, interesting and simple sport, letting more people come into contact with football, communicate through football matches, and fully enjoy the fun brought by football, so it is also called the grass-roots football program. And our country's campus football is the embodiment of a grassroots football sport with Chinese characteristics.

The Development Background of Campus Football. The State Sports Bureau, in conjunction with the Ministry of Education and other relevant departments, put forward a call for the development of campus football in our country. The aim is to let more teenagers join in the process of sports, so that more teenagers can experience the fun that football brings to them, so that teenagers cannot only exercise through football, but also help teenagers develop the sense of team spirit and group cooperation through football.

The Culture Connotation of Campus Football. Our country's campus football culture is a kind of football culture carried out within the specific scope of campus. It is to promote friendship between teachers and students through football, to complete the all-round development of morality, 
intelligence, physique and beauty of teenagers through football, to improve the physical quality of teenagers through football, to make them love football more, and to find and select football talents for our country's football and to promote the development of our country's football. Our country's campus football culture is a special kind of football culture, which is mainly based on football teaching and supplemented by extra-curricular football sports. The purpose is to cultivate teenagers' interest in football, enable them to take an active part in football and make their physical functions develop harmoniously. Campus football culture does not only embody the characteristics of football culture, but also has the characteristics of campus culture. It is an organic combination of the two and provides a new model for football development.

\section{Strategic Analysis of Normal Development of Campus Football in Colleges and Universities}

To promote the development of campus football needs to start from many small details. At present, some colleges and universities do not attach special importance to football teaching, and students are less motivated to participate in football teaching. The Ministry of Education has put football education on the agenda. Attaching importance to the development of national football must begin from the campus. In order to promote the normal development of China's football cause, colleges and universities must carry out more football-related sports activities in order to attach importance to the development of campus football activities.

To realize the normalization of football talent training and the development of college students

In many world-class competitions, our football has always been at a disadvantage, which is a great challenge for China to carry out sports activities related to football. Trying to improve the level of football in our country can take the cultivation of talents as a breakthrough to improve the development level of football in our country as a whole. In the university campus, sports activities are not uncommon. Proper sports can exercise students' physical quality and cultivate their sense of team cooperation and comprehensive quality.

To promote the normalization of campus football activities and other sports activities

In the process of college students participating in football exercises, as a sport with strong antagonism and team cooperation, football can effectively enhance students' competitive consciousness and fighting spirit. In the university campus, various sports activities are common, including basketball, volleyball, table tennis, tennis, badminton, yoga, health care and so on. The sports subjects of interest to different students are also different. In the process of promoting the development of campus football, colleges and universities should see some gains brought to students by other sports activities and pay attention to the balance and diversification of other sports teaching, so as to better cultivate the comprehensive quality of college students.

To achieve the coordination between campus football competition and popularization

The goal of campus football is to promote students' physical and mental health. From the current situation of our country's campus football, it shows certain utilitarianism, such as excessive pursuit of football results, pursuit of formal football and so on, which makes the popularization and promotion of campus football unable to develop normally and institutionally and is not conducive to the sustainable development of campus football in China.

\section{Strategic Analysis of Institutionalized Construction of Campus Football in Colleges and Universities}

In order to promote the development of campus football, we must establish and improve the relevant system of colleges and universities, which is the basis to promote the development of campus football activities.

To improve the evaluation system of campus football

Nowadays, many people don't know much about campus football activities and the importance of the development of it. Colleges and universities must improve the relevant evaluation system in order to speed up the promotion of football activities. The evaluation system of campus football can effectively promote the development of campus football, including the teaching, training and 
competition of campus football. The evaluation system should focus on some possible problems in the development of football activities, reasonably evaluate the development of football activities at this stage, and improve students' learning enthusiasm to some extent. An effective evaluation system can guarantee the conditions for the development of football, which can lay a foundation for the development of football in the later period.

To establish and improve relevant football majors

Football activities can become a professional course for students. Many sports study will choose a sports activity as specialty for training. Football can naturally become one of students' choices. In the daily football training, teachers first let students have a preliminary understanding of football-related common sense, and then gradually let students learn relevant football skills. The setting of football major is of great significance to stimulate colleges and universities to develop campus football from an innovative perspective, to examine campus football with a healthy attitude, and to expand campus football in a popular way.

To establish and improve the selection and evaluation system of colleges and universities with campus football

Constructing the selection and evaluation mechanism of campus football is an important breakthrough to promote the institutionalized development of campus football. From the current distribution of campus football in our country, the number of distribution and characteristic colleges and universities is constantly increasing, and campus football is showing a prosperous scene in number. Under such a background, the evaluation and upgrading of distribution and characteristic colleges and universities has become a way to improve the enthusiasm and effectiveness of football work in such colleges and universities. The evaluation and upgrading of campus football is of great significance to inspire colleges and universities to develop campus football from an innovative perspective, to examine campus football with a healthy attitude and to expand campus football in a popular way.

\section{Conclusion}

To sum up, campus football is an effective platform to promote the healthy development of college students' body and mind and to promote the mass and foundation of Chinese football. In order to better realize the sustainable development of campus football, it is necessary to increase the normalization and institutionalization of campus football. The normalization of campus football is realized on the basis of the normalization of the popularization of campus football, the development of campus football matches and the flow of football talents on campus. In this process, we should aim at the healthy development of college students' body and mind, and take the construction of the teaching content system, the management system, the talent training system and the exchange system of campus football as the starting point, so as to promote the normalization and institutionalization of the development of campus football and realize the sustainable development of campus football in our country.

\section{References}

[1] Steinfeldt J A, Gilchrist G A, Halterman A W, et al. Drive for muscularity and conformity to masculine norms among college football players[J]. Psychology of Men \& Masculinity, 2011, 12(4):324-338.

[2] Boden B P, Tacchetti R L, Cantu R C, et al. Catastrophic cervical spine injuries in high school and college football players[J]. American Journal of Sports Medicine, 2006, 34(8):1223.

[3] Meyers M C. Incidence, mechanisms, and severity of game-related college football injuries on FieldTurf versus natural grass: a 3-year prospective study[J]. American Journal of Sports Medicine, 2010, 38(4):687-97.

[4] Football T L. College football data warehouse[J]. 2015.

[5] Hoffman J R, Ratamess N A, Klatt M, et al. Comparison between different off-season resistance training programs in Division III American college football players[J]. Journal of Strength \& 
Conditioning Research, 2009, 23(1):11.

[6] Glassman T, Werch C E, Jobli E, et al. Alcohol-related fan behavior on college football game day[J]. Journal of American College Health, 2007, 56(3):255-260.

[7] Boden B P, Breit I, Beachler J A, et al. Fatalities in high school and college football players[J]. American Journal of Sports Medicine, 2013, 41(5):1108-16.

[8] Brechue W F, Mayhew J L, Piper F C. Characteristics of sprint performance in college football players[J]. Journal of Strength \& Conditioning Research, 2010, 24(5):1169-78.

[9] Butler R J, Lehr M E, Fink M L, et al. Dynamic balance performance and noncontact lower extremity injury in college football players: an initial study[J]. Sports Health, 2013, 5(5):417-422.

[10] Gwacham N, Wagner D R. Acute effects of a caffeine-taurine energy drink on repeated sprint performance of American college football players[J]. International Journal of Sport Nutrition \& Exercise Metabolism, 2012, 22(2):109.

[11] Fréchette G R, Roth A E, Ünver M U. Unraveling Yields Inefficient Matchings: Evidence from Post-Season College Football Bowls[J]. Rand Journal of Economics, 2007, 38(4):967-982.

[12] Mayhew J L, Houser J J, Briney B B, et al. Comparison between hand and electronic timing of 40 -yd dash performance in college football players[J]. Journal of Strength \& Conditioning Research, 2010, 24(2):447-451. 